\title{
Investigation of a Significant Slide in the Embankment of an Old Dam
}

\author{
Sukhmander Singh ${ }^{1}$ \\ ${ }^{1}$ Santa Clara University \\ 500 El Camino Real, Santa Clara, United States \\ ssingh@scu.edu
}

\begin{abstract}
Shortly after construction was completed, a significant slide occurred in the lower portion of the embankment of an earth dam built in the period 1920-22 but did not affect the function of the reservoir (140 x 180 feet in plain view). Between 1922-1930 various remedies to fix the slide were tried but the slide kept moving downhill during rainy season. Monitoring of water table in the sliding area and stability analysis in the past (during 1970s) indicated a safe slope. The embankment was remodeled slightly in 1954, 1956 , and 1971. However, the embankment section in the old slide area remained a matter of serious concern; because Hayward fault is located about $1000 \mathrm{ft}$. East of the dam and a preliminary analysis indicated the dam to be unsafe during an earthquake event. Yet, the movement was observed during the rainy season. Finally, in 1980, a comprehensive field and laboratory investigation revealed an important but significant information that escaped previous investigations. The stability analysis of the past had failed to identify the failure surface. The surface of sliding was due to a very thin and highly plastic clay layer that was discovered in 1980 by a combination of boring and in-situ cone testing. This combination was also helpful in reaching at the appropriate strength parameters of the highly plastic clay layer which was at its residual angle of friction. This lead to the conclusion to remove the clay layer. The paper presents the details of how the discovery of the thin clay layer. Also presented briefly the remedial measures adopted to replace the clay layer by a free draining granular soil layer. This was achieved by emptying the reservoir and excavating the overlying embankment material and re-compacted it back after the replacement of the clay layer. The paper discusses the importance of combining Geotechnical and Geological details in establishing what is down there (the subsurface profile). The paper briefly presents the remedial measures to fix the slide.
\end{abstract}

Keywords: Sliding for years, Sliding Surface, Detection by Cone Testing.

\section{Introduction}

35 foot-high earth dam was constructed in the period 1920-1922 in the base of Berkeley Hill, in the San Francisco Bay Area. The reservoir was made by cutting into the natural slope with a cut on the uphill side and constructing an earthen embankment on the downhill side. Shortly after construction was completed a significant slide (140 by 180 feet in plan view) occurred in the lower portion of the embankment (See Figure 1). The dam history revealed that between 1922 and 1930, the slide continued moving slowly downhill during the rainy season, during which period, various remedies to fix the slide were tried. At one time, the slide was broken up by shooting with dynamite to destroy the sling surface if any. Later 1400 cubic yards of quarry rock was dumped on the top of the slide hoping it would work downwards into the slide mass and take hold of the harder formation. But none of the remedies worked. In 1980, a comprehensive field and laboratory investigation was undertaken. Static and simplified dynamic stability analysis originally indicated a safe slope, but it required a close examination of subsurface soils. The paper describes how a combination of boring and in-situ cone testing were helpful in discovering the failure surface due to a very thin and highly plastic residual clay layer. 


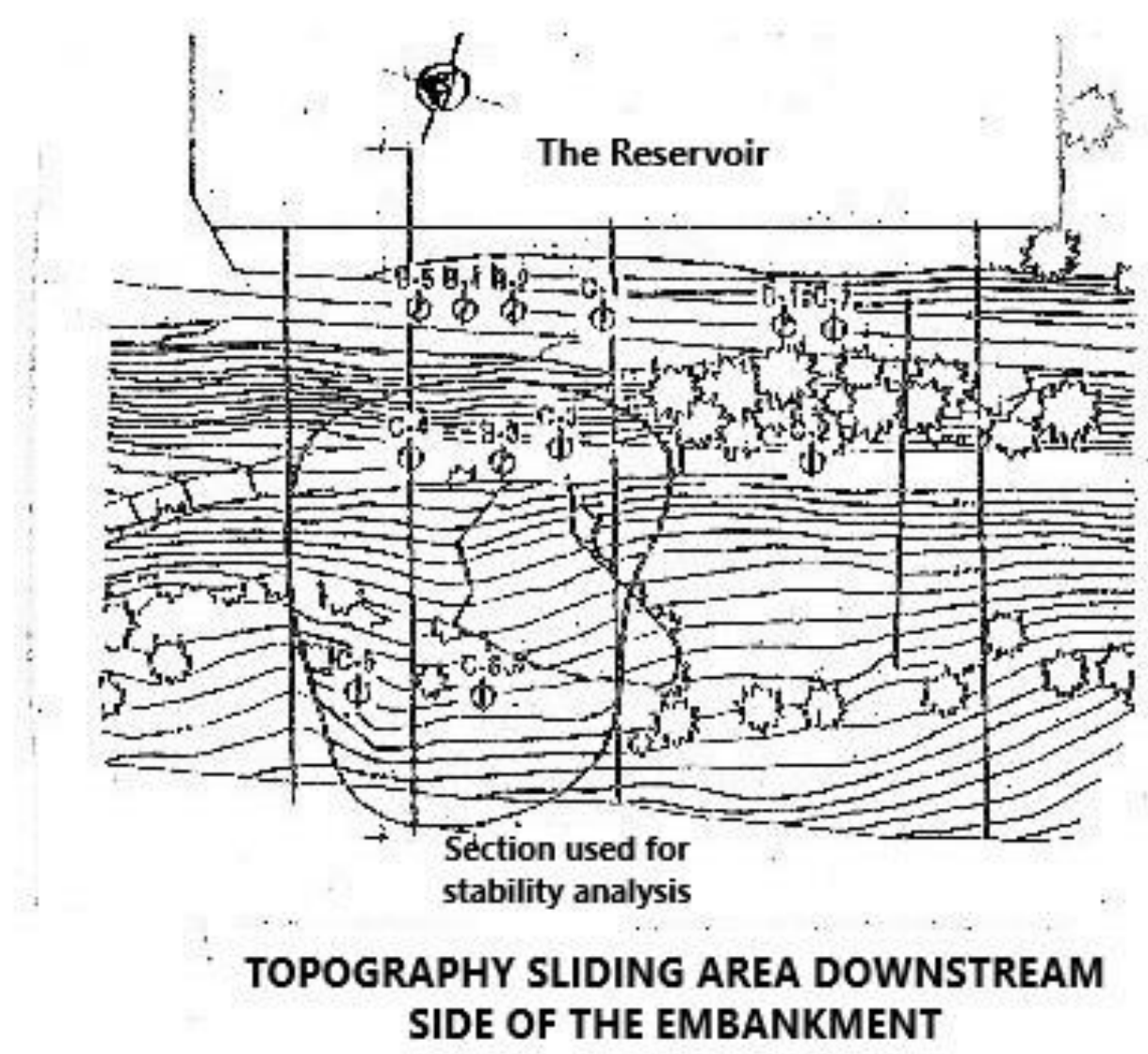

Fig. 1.

\section{Site Condition and Embankment Material}

The four soil borings on the crest and two for geophysical study indicated brown and gray, sandy, silty, gravely clay (GC-C2) from a depth of 0 to 25 feet. Geologic repost (Masliave, 1971) discovered the Franciscan bedrock formation of the dam site, most of the surface exposure are highly weathered. The dry density of the embankment material ranged from 98 to 115 per cubic foot and water content ranged from 14 to 25 percent. The strength parameters with respect to effective stresses were $\varphi=29^{\circ}$ to $32^{\circ}$ and $c=0$ to 100 pounds per square foot. Since the construction records were not available, it was not possible to establish the manner in which the fill was placed. The figure below shows the schematic soil profile. 


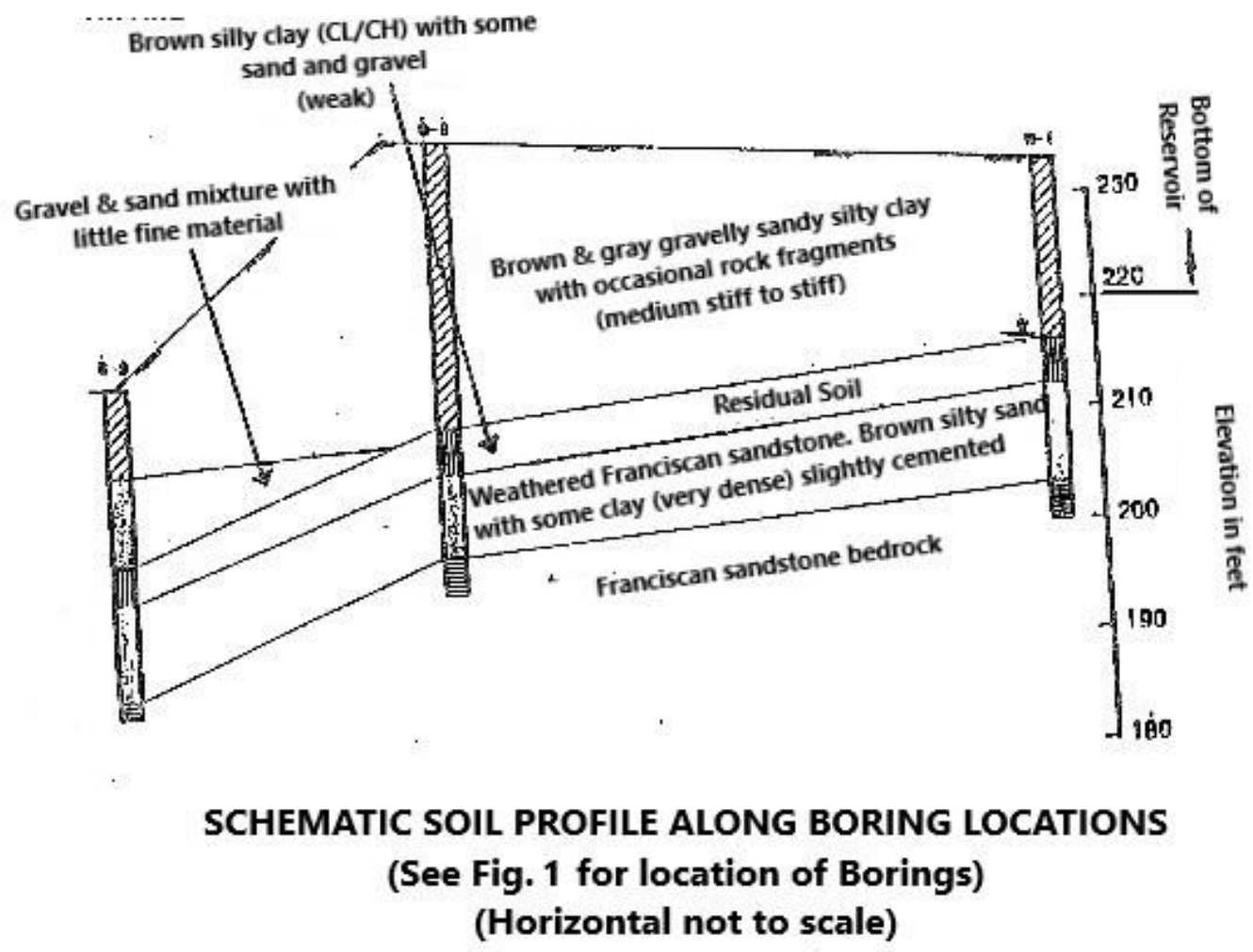

Fig. 2.

\section{Stability Analyses}

For static stability analysis of the slide area, the presence of a relatively weak, highly plastic clay layer (5 to 8 feet thick) overlying the bedrock was considered to be significant. Accordingly, the critical mode of failure was considered to be a planar block slide panning through the clay layer. A computer program developed U.C. Berkeley (Ceteslino and Duncan, 1980) that performs an automatic search for critical noncircular surfaces was used for stability analysis for the cross section shown in fig 3.

Fig 3 


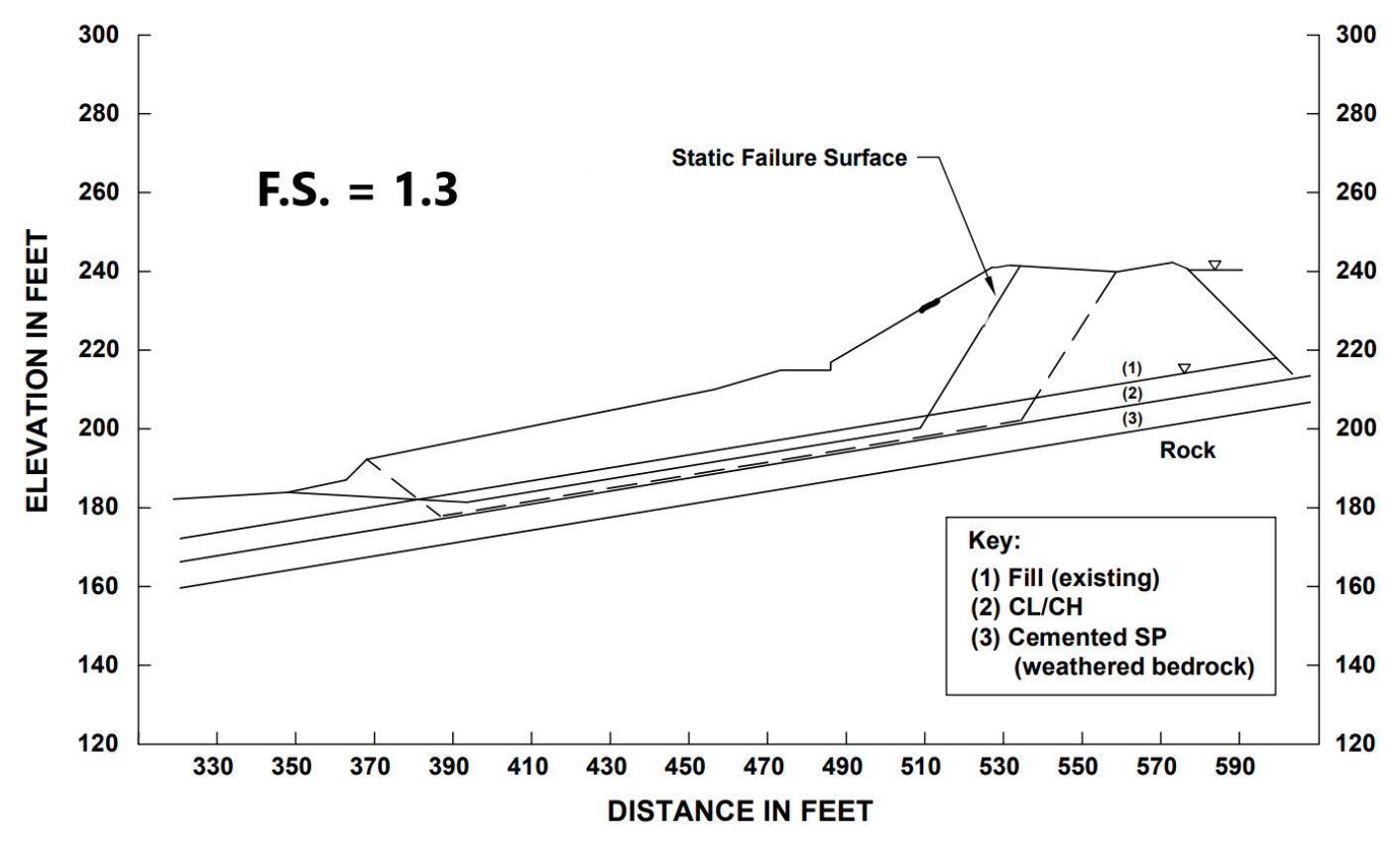

STATIC STABILITY ANALYSIS - 1981 Cross Section

Fig. 3.

This cross-section was based upon documented topographic maps (Clyde 1930, Franklin and Dayton, 1972) and groundwater elevations noted in 1930. The factor of safety came out to be much higher than unity which contradicted to the fact that the slide was slowly moving. A close examination of the strength parameters was warranted. Since it was difficult to retrieve high quality, undisturbed samples of a thin, highly plastic clay layer by boring and sampling, cone penetration testing was performed at six different locations. Figure 4 shows the cross-section showing CPT test results.

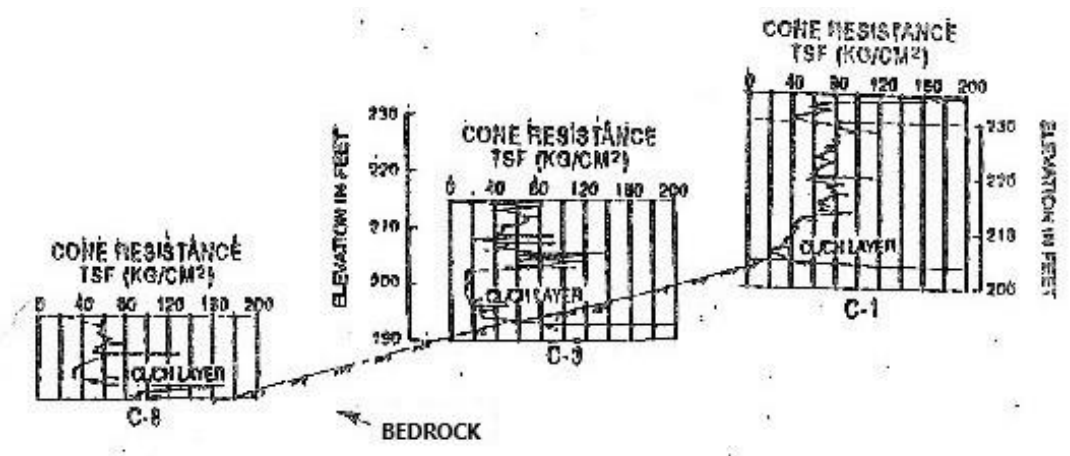

Fig 4 SECTION THRU CONE-PENETROMETER TEST HOLES
(REFER TO Fig. 1 FOR LOCATION OF CPT HOLES) 


\section{Discussion}

The cone resistance revealed significant drop in the highly plastic layer. This significant drop was just above the bedrock and below the embankment material (fig. 4). The most critical observation was that the strength indicated by cone resistance was much lower than the strength value obtained by laboratory testing of samples. It was argued that due to the sloping topography and the long-term loading on the clay layer might have resulted in its residual strength value. Accordingly a laboratory testing program to evaluate residual strength of the clay was undertaken. A number of tests under drained direct shear conditions with reversal of strain direction to induce residual strength performed on the clay samples. A residual angle of friction came out to be $16^{\circ}$, which was much less than the $30^{\circ}$ used in the earlier stability analysis. The cone test results were also helpful to more accurately indicate the thickness as well as the continuity of the clay layer. Thereby reinforcing the idea that it was this clay layer which provided the original slip surface of sliding.

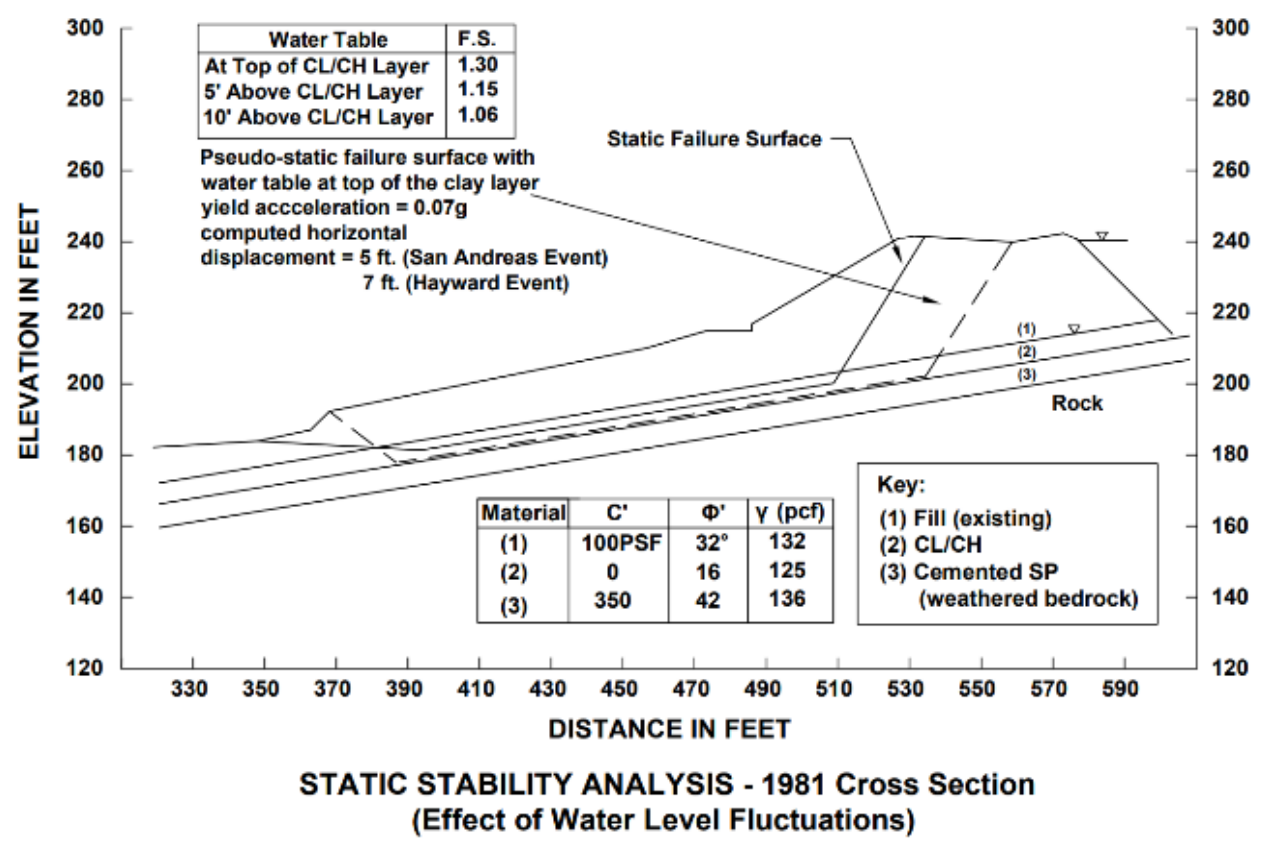

Fig. 5.

The safety factor came out to about unity which matched with the sliding that has been occurring over the years. In order to resolve why the slide had been moving during the raining season, additional analyses were carried out to evaluate the effect of water table fluctuatios. Attention to details in the development of the subsurface profile and the application of the in-situ cone testing technique were helpful in defining the failure surface and in arriving at the correct soil strength parameters. The foregoing results made it clear that the most effective means of improving the stability of the embankment would be to remove as much of the weak clay layer as is possible and replace by a free draining material. Remedied measure to improve the stability of the dam involved removing as much of the weak clay layer as possible, which was undertaken after emptying the reservoir and by replacing the removed clay layer with free draining granular material.

\section{Conclusion}

1. In the development of subsurface profile, attention to details in combination of geotechnical and geological aspects played a significant role. 
2. Cone penetration testing technique in combination with boring, sampling and laboratory testing not only helped in defining the thin weak surface of sliding, but also in arriving of the correct strength parameters for the weak layer which had reached at its residual strength value which otherwise could not have been discovered.

3. It is important to consider the fluctuations of water table conditions in stability evaluations. A close examination of old records were helpful in establishing the water table with in the embankment before and after the slide.

\section{Acknowledgements}

Sincerest appreciation to Anthony Orciuoli, Melanie Massie, and Mason McCollum for their help in the preparation of this paper.

\section{References}

[1] T. B. Celestino, and J. M. Duncan, "NONCIR: A computer Program for Slope Stability Analysis with Automatic Search for Critical Non-Circular Slip Surfaces," Geotechnical Engineering, Dept. of Civil Engineering, University of California, Berkeley. 1980.

[2] H. S. Clyde, "Investigation of Sliding Area Below Clearwell, San Pablo Filter Plant," East Bay Municipal Utility District. Report, 1930.

[3] R. Fishkin, and D. J. Dayton, "San Pablo Filler Plant Clearwell Stability Investigation and Analysis," East Bay Municipal Utility District. Report, 1972.

[4] B. H. Marliave, "Geologic Review of San Pablo Clearwell," a letter report submitted to Mr. D.G. Larkin, Chief Engineer, East Bay Municipal Utility District. Report, 1971. 